\title{
The silent biological Hiroshima: GMOs-Induced Darwinian devolution of human race
}

\author{
JH Wassili and Cyril Baradaeus* \\ The Samaritan Biochemists, 279 Khaled ben Walied, Seidi Gaber, Alexandria, Egypt \\ You can chain me, you can torture me, you can even destroy this body, but you will never imprison my mind.
}

\begin{abstract}
Abbreviations
GM: Genetic modification; GMOs: Genetically modified organisms; FDA: Food and drug administration; AaHIT: Androctonus australian hector insect toxin; ICC: International criminal court; Bt: Bacillus thuringiensis; GNA: Galanthus nivalis agglutinin; GH: Growth hormone; rBGH: Recombinant bovine growth hormone; IGF-1: Insulin-like growth factor-1; RRS: GM roundup ready soybeans
\end{abstract}

\section{Summary}

While abhorrently waving the slogan of technical supremacy, untamed human greed goaded the maximal extraction of earthly natural wealth with the absolute minimal concern, if any at all, to sustain the depleted environment. Thus, green lands and rivers became the sewage bowl to the refuse of the petrochemicals, herbicides, pesticides, cosmetics industries, etc. A scrutinising glance at the shelves of a hardware store would reveal the range of polluting chemicals produce as of paints, lubricants, wide-range of adhesives, epoxy cement, ceramics, plastic tubes, increased plastic and polymeric ingredients within kitchen necessities as refrigerators, vacuum cleaners, coffee machines, dishes, cups, forks, knives, spoons, etc. It is no coincidence; the plague of industrial-pollution of the environment has substantially increased as of the 1950 s $10 \%$ obesity to $36 \%$ in 2012 (addiction to antibiotics?), malignancies, psychological, de novo bacterial and viral ailments resistant to known medications, megabacteria and genetic disorders. For example, proportions of children with autism spectrum disorder have increased since 1950 to reach 1 every 68 newly born infants in 2017, characteristically 1 in 42 for males and 1 in 189 for females. Our reading of this observation is a specific intoxicant-induced selective genetic damage to males' sperm over and above the organic damage which modulated deformation, sluggish and weaker male sperm. Thus, the currently observed world-wide increased proportions of newly born females vis-à-vis fewer and frail male babies. Rightly so, within the medical community, these statistics precipitated fear of a pandemic of autism. The same thespians who advocated the production of pesticides and herbicides, which induced malignant toxicities and plagues of health hazards, trumpeted the latest pseudo-scientific gamble; that is attractively polished as the modern biotechnological superiority of GMOs to produce more food in hostilearid milieu. GMOs are synthetic reagents which will detour the welldefined medical vehicles as cardiovascular diseases, malignancies, hepatic, gastric, kidney and pancreatic functions, etc., into absolutely different highways. It is a long acting biological Hiroshima silently obliterating whatever left of human race; the few individuals who are barely healthy and the predominantly intoxicated ones.
The wisdom of Hunter S. Thompson "The truth, when you finally chase it down, is almost always far worse than your darkest visions and fear", is a true portrayal of the (i) envisaged venomous impact of GMOs on humans' health and (ii) disastrous environmental intoxication. However, the well-articulated conclusion of the master genius Dr. Henry Kissinger "Control oil and you control nations; control food and you control the people" best describes the Machiavellian drive of the pharmaceuticals and multinationals to genetically engineer and/ or mutate the primary organic source of humans' daily sustenance, e.g., animals, fish and plant harvests. This presentation is a typical review of organic chemists into the morass of the transgenesis of plants and its anticipated negative impact on health of consumers. In route to Kissinger's conclusion, 'academic capitalism' was budded. That is higher learning institutions; universities and generations of specifically post-graduates are mentally disfigured and became enthusiastically dependent on and are acclimatized to the so-called biotechnology private research funding. Thus, the new orientation and conclusions of the successfully funded programs are coined in favor of GMOs for a variety of $\$$ amassing adventures, e.g., medical as in making artificial ligaments, tendons for eye surface and jaw repair, GM edited plants and transgenic fruits to embrace hepatitis B and cholera vaccines respectively, industrial applications as in bulletproof vests and car air bags, incorporating spider silk spinning proteins into the biological machinery of producing goat milk [1], etc.

Rather than rigorous and impartial scientific quest into the pro and cons of synthetic GMOs in terms of adequate analysis of the genetic and proteomic stability of transgenic products in animal models, pillars of the biotechnology industry infiltrated and dominated the US federal regulatory bodies and universities. Thus, the approval of the release of synthetic GMOs as a safe nutrient for consumption was orchestrated with deliberate disregard to all anticipated negative impacts of GMOs on humans and environment. This murky scheme necessitated the absolute silencing of opposing points of views, e.g., the case of GE Seralini, et al.

At this concomitance, regardless of degrees of intensive learnings, it should be appropriate to the readers to grasp the \$-driven exploits of:

1) The so-called "humanitarian" drive to introduce GM bananas to feed the poverty stricken Ugandans!!! Incidentally Uganda superintends a vast richness of green land and a part of one of the largest African fresh water reservoir, Lake Victoria. That is almost

Correspondence to: Cyril Baradaeus, The Samaritan Biochemists, 279 Khaled ben Walied, Seidi Gaber, Alexandria, Egypt, E-mail: bioscience001@yahoo.com

Received: January 19, 2018; Accepted: February 14, 2018; Published: February 17,2018 
reminiscent to the humanitarian massive inoculation against polio in Uganda which is suspected as the causative factor behind the plague of AIDS, with consequent loss of manpower, staggering poverty and famine in that stricken African nation. After 27 million deaths and the infection of more than 66 million with HIV, there is a strong indication that human hands specifically scientists of multinational pharmaceuticals are to blame for the eruption of the AIDS pandemic in its entirety [1], and

2) The expected menaces of shuttling the risky edited GMOs' genes into consumer's DNA and environmental domain, e.g., one of the very many is the scorpion gene hybridized into cabbage's DNA.

In brief, hazards of hosting de novo long range medical afflictions of GMOs prepared in few hours in petri dishes to humans' DNA and cellular domain are deemed unsurmountable. What if the genome of these genetically edited AaHIT scorpion-seeds could laterally/ horizontally added to bacteria and humans' DNA?

Ultimately, this calculated stratagem yields the systemic devastation of natural environment, as of bacteria feeding on remnants of diets prepared from GMOs lots, passage of human's excrements, faeces and urine, into adjacent environment as water circulation, soil, etc. To make things worse, it is almost a large scale seizure of the natural mechanisms dealing with extraction of nature's wealth and produce by the few GMOs-Pharmaceutical manufacturers. Thus, worldwide farming is cartelized and limited to few multinational- biotechnology concerns' manufacturing GMOs seeds, viz., Bayer purchased Monsanto! Accordingly availability of GMOs grains to international markets would be remotely controlled by the very few GMOs' multinationals according to the political obedience of the recipient governments. In brief, it is the political hegemony of the masses by the exploits of biotechnology!

Contrary to the GMO advocates' claim: protocols of genetic engineering are precise and yield reproducible yield of GMOs; genetic engineering is at its infancy, i.e., imprecise laboratory procedures which yield irreproducible genetically structured variants, indeed. Like so, transgenesis of seeds allows unpredictable structural modification in the DNA and cellular proteins of the synthetic GMOs seeds. The major impact of these GMOs on consumers' integrity is most probably the de novo incidents of cellular mutations and precipitation of allergies in animals and humans, irrevocable environmental intoxication, depletion of consumers' immune-system, etc.

To top it; (a) transgenic cotton expressing synthesized scorpion AaHIT toxin gene is claimed to enhance resistance to cotton bollworm and (b) genetically manipulated mosquitos are manufactured under the pretence of controlling malaria [1]? Viz., Layton J; Can genetically modified mosquitoes wipe out malaria? Science, Howstuffworks, Science.Howstuffworks.com/life/genetic/gm-mosquito.htm. According to a recent assumption; GMO mosquitoes are the causative factor behind the outbreak of Zika virus, dengue fever, yellow fever and microcephaly insults; viz., www.Snopes.com/fact-check/Zika-virus-gmo-mosquitoes. What are the side effects of imprecise genetic editing of mosquitos? Entertaining events as of the incipience of the phenomenon of antibacterial application known to the Ancient Egyptians who applied the dressing of moldy bread to infected wounds until the large-scale production of and addiction to antibiotics, generations of bacteria underwent a slow and well recognized genetic edition to yield new strains of bacteria resistant to known antibiotic. According to this course of evolution on the long run, one of the anticipated hazards of GM mosquitoes is most likely the evolution of a super-mosquito with enhanced mechanistic efficiency of microbial delivery into recipient's circulation?
To have the reader on the same wavelength of the time span necessary to attain cellular evolution, let us dig deeper in the aspect of the Evolutionary Origin of the Mitochondria as a simple and early investigative yardstick to Human Creation and Evolution. With the exception of chloroplasts, mitochondria appear to originate solely from other mitochondria. They contain their own DNA, which is circular with their own transcriptional and translational mechanisms as with bacteria. Human's mitochondrial ribosomes and transfer RNA molecules are similar to those of bacteria, as are foundations of their membrane which may suggest the mitochondria of the immaculate last form of billion years of evolutionary process, human, is from a bacterial origin. Most valuable is the reporting of CP Williams (Science March $16,2015)$ pertaining to humans may harbour more than 100 genes from other organisms.

According to the endosymbiotic hypothesis, the mitochondria are about 3.8 billion years descendant of specific bacteria which survived endocytosis by another species of prokaryote, i.e., hosts' cytoplasmic incorporation. Arguably, how much time has elapsed to have a single lineage split into distinct species which are different from each other at the molecular level? That is considering all possible mechanisms of billions of years of nature's step-limiting Darwinian's evolution to yield the supposedly immaculate ultra-complex humans, it could undergo an accelerated downgrading in response to lateral and/ or horizontal insertion of DNA manipulated GMOs into mammals genome. Alas, it is a Biological Hiroshima triggering an irrevocable Darwinian devolution?

\section{Introduction}

GM is the in-vitro editing of a living organism; animals, plants and/ or microorganisms' genome to yield a new entity with different biological function(s). Hybridization of genes in between different species, i.e., recombinant DNA technology, affords GMOs or transgenic organisms. It is entirely uncertain to speculate on how these transgenic modifications would limit the biological specificities of the new entity within the approximation of the biological description of the authors' "Results and Discussion" section? Therefore, the urgency of organic chemists to critically delve into the issue of GMOs with the utmost circumspection is absolutely warranted as probable disfigurements of bacterial, animal and human cellular domain and risks of irrevocable intoxication of the environment are expected. Nonetheless, the GMOs are penetratingly marketed with salivating advertisements as the cellophane wrapped miracle of the ingenious biotechnical superiority that is specifically designed to minimize herbicidal and insecticidal intoxication of the environment and ultimately leading to managing droughts, scarcity of food supply in underdeveloped countries, etc. Amazing, the same very manufacturers who vigorously marketed pesticides and herbicides some decades ago on the account of improving yields and avail healthier, better tasting, improved texture and price-wise affordable harvests to consumers are the same very ones crying wolves while marketing of the GMOs as the safe alternative to polluting agents, pesticides and herbicides?

Currently, China is leading the commercialization of a transgenicvirus resistant tobacco. Would smoking GMO tobacco boost the precipitation of 2nd hand smoking-lung cancer? The unsettling presentation of increased rates of lung cancer as of 1950, Figure 1, strongly shed doubts on the wisdom of commercializing transgenicvirus resistant tobacco. In this conjunction, we may add; the exponential increase in lung cancer's death as per Figure 1 within a period of 40 years cannot be solely due smoking and/ or second-hand smoking specially 


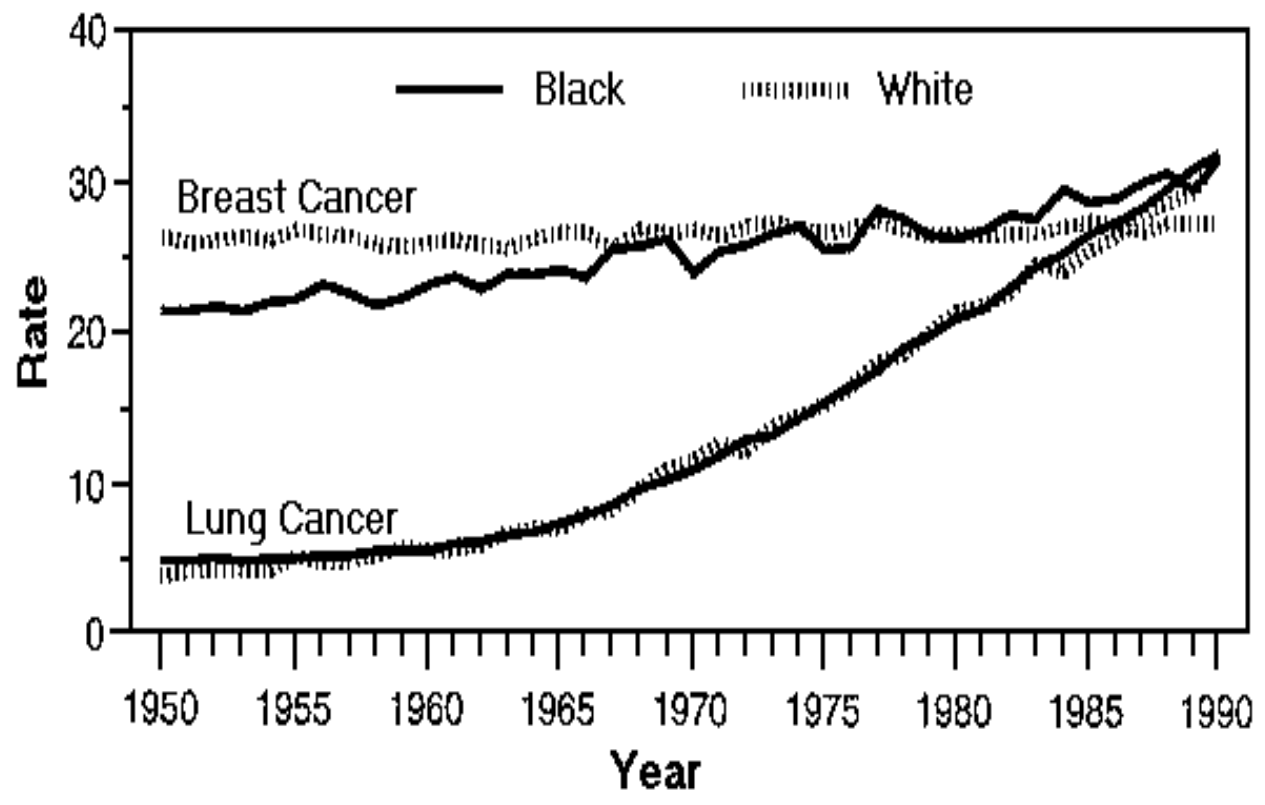

× Per 100,000 women, standardized to the 1970 age distribution of the U.S. population.

Figure 1. Centre for Disease Control and Prevention November 12, 1993

number of smoking females aged, 18 years and older, marginally decreased during the period 1965 to 1980 . Substantially damaging is the 24 hours a day inhaling toxic car exhaust. This major contributor to death and pollution remains to be tackled, unfortunately by the military industrial complex associated with crude oil trade and industry.

The transgenic 'Flavr Savr' and delay-ripening tomato (CGN89564-2) was 1994-FDA approved and coined "safe as tomatoes bred by conventional means". The rational cited was: the use of aminoglycoside 3'-phophsotransferase II is safe for the development of GMO tomato, rapeseed oil and cotton? In the first place; how did the FDA conclude with absolute certainty the safety of aminoglycoside 3'-phophsotransferase II? A year later, although with different triacylglycerol composition, the FDA hastily approved the transgenic canola; US Food \& Drug Administration, fda.gov/Food/Ingredients Packaging Labeling/GE Plants/ucm461805.htm. Worse is the FDA's recommendation, which negated the basics and essence of consumer's right in a so-called free market-democratic society, to categorise the basic quality of their sustenance. In brief the FDA vouched against labelling GMO products as in-vitro manipulated commodities? Theoretically, how will artificial GM canola oil with different spectrum of triacylglycerols would affect the specificities of fatty acids distribution (unsaturation and length of fatty acids) along the glycerol chain of lipids deposited around and within various tissues of bodily organs in humans, e.g., muscle, arterial, heart, liver, kidney, etc.? Logically, how these differences in fatty acids arrangement will affect the integrity and efficacy of a given organ? For example, any compositional variations in LDL and HDL and how these variations will reflect on the maximal and minimal limits of these two diagnostic factors as pointers to heart's performance?

In general, daily subsistence on GMOs' enriched diets may limit the diagnostic boundaries of factors released in serum's circulation by various organs, e.g., hepatic, pancreatic and cardiac enzymes and kidneys' released substrates as albumin, urea, uric acid, acetone, etc.? Appropriately, what are the de novo indicative limits to these serum circulating factors for healthy and GMO-ailing organs? Obviously, this quest requires organic chemist's re-visitation of the diagnostics drawing board? This is to formulate new kits with specifically new compositions and a different range of analytical limits characteristic of healthy and/ or ailing organ? In case it does, prohibitive expenses are foreseeable while searching for availing new diagnostic kits, appraisal of uncertainties involved in serum-chemistry diagnosis, designing appropriate medical procedures and protocols necessary for the treatment and medication of the newly GMOs-induced diseases. How the currently crippled two-tier medical care and medical insurance companies will deal with GMOs' newly developed maladies in the dispossessed, middle class and healthy segments of the populace? Most urgent is the expected devastation associated with the invasions of the de novo second-generation GMOs-induced bacterial and/ or viral mutants into the population of the GMOs' compromised homeless until all-inclusive medical care bill covering the minimal necessities of the disadvantaged and homeless will ever materialize? Of course, assuming the all-inclusive medical care coverage of the homeless could ever escape the vultures of the many groups of interest, It is endless?

Similarly, GMOs' harvests resistant to the herbicide bromoxynil, Bt corn, cotton, Bt potatoes, soybeans resistant to the herbicide glyphosate, virus-resistant squash were injudiciously approved as well. As of 2011, the USA leads the list of countries producing GMOs with the least scientific justification, if there is any at all.

The issue of synthetic GMOs versus organic strains is rather a controversial issue that is shrouded with abundant uncertainties. This is mainly due to the scarcity of published inquiries pertaining to long range experiments in animal model on the half-life time of various GMOs to manifest anticipated toxicity. Apart from the blitzkrieg of colourful pro-GMOs advertisements, it is deemed essential to carry out an adequate basic organic chemistry search at the molecular level to ascertain the safety of GMOs products, i.e., absolutely void of the remotest possibilities of lateral and/ or horizontal genetic insertion of edited portion of GMOs into mammalian, bacterial and/ or viral genome. The de facto is the domineering Capitalism of pseudo-science 
made it possible for the multinationals to release GMOs' varieties for public consumption without any adequate toxicological inquisition. Thus, probability of inflicting a wide range of maladies into consumers' realm, e.g., infertility, cardiovascular diseases, mutagenesis, allergies, gastrointestinal and pancreatic aberrations, kidney and hepatic insufficiencies, neural irregularities, etc., is very probable. It is very feasible as well; recycled by-products of GMOs' consumption, viz., human's excretions, remnants of unconsumed GMOs may lead to irrevocable intoxications of environment and available natural resources which will turn the science of environmental scrubbing and renewable resources into irrelevancy.

An example of the exaggerated and bombastic blitz in favour of GMOs' safe consumption is an electronic circular entitled "29-year study of trillions of meals shows GE crops do not harm food-producing animals, human" [Genetic Literacy Project. Science not Ideology]. Typically, this electronic text did unscientifically settle to claim: there were no indications of any unusual trends in the health of animals since 1996 when GMO crops were first harvested. Considering the size of the dataset, it can reasonably be said that the debate over the impact of GE feed on animal health is closed: there is zero extraordinary impact. Nevertheless, according to:

(I) American Diabetes Association: 1995 and 2010's diabetic incidents were 4.5 and $8.2 \%$ respectively in the USA. In $2015,84.1$ million age 18 years and older are diagnosed pre-diabetic,

(II) American Heart Association: In 2017 as much as 2200 Americans died of cardiac vascular diseases per day, that is almost 1 mortality per 40 second, and

(III) According to liver cirrhosis statistics: Figure 2, Centre for Disease Control and Prevention, is self-explanatory.

Considering examples of above statistical ailments (I)-(III), it is deemed imperative to inquire into the potential association of the above multiplying ailments with increased consumptions of GMOs?
Further, the author of Genetic Literacy Project. Science not Ideology stated: No study has revealed any differences in the nutritional profile of animal products derived from GE-fed animals. Because DNA and protein are normal components of the diet that are digested, there are no detectable or reliably quantifiable traces of GE components in milk, meat, and eggs following consumption of GE feed. À la the above detailed portrayal of the time span elapsed as of inserting bacterial mitochondria as an organelle with a specified function into mammalian cells; it would take more than the utterly naïve claim above of 29-years study to evocatively palpate the toxic side effects of the GMOs which are already marketed for humans' dietary intake in terms of toxicity to consumers and the environment. In this context, it is interesting to speculate on the consequences of humans' assimilation of a latter-day evolved GM-Candida albicans. Candida albicans, a common opportunistic pathogenic yeast of human gut flora, is recognized as a pointer to diabetes mellitus and malignant tumors. Environmental pollution with GMOs refuse may irrevocably modulates the functionalities of bacterial vaginosis that is associated with $>357 \%$ increase in the incidence of cervical intraepithelial neoplasia. Harmful effects to animals and humans have also been noticed:

(i) milk of cows treated with rBGH leads to an increase IGF-1, a primary mediator of the effect of $\mathrm{GH}$ which according to some scientists, may stimulate growth of cancer cells [2] and

(ii) Bt-toxins released by GM maize MON810 can significantly impact the viability of human cells [2].

Male mice fed for $15 \mathrm{~d}$ Bt-toxin-transgenic potatoes; did not develop dramatic changes in the ileum of the animal vis-à-vis individuals fed on potatoes treated with $\beta$-endotoxin (30 minutes freshly cut small pieces immersed in a suspension of $\beta$-endotoxin $1 \mathrm{~g} \mathrm{l}^{-1}$ distilled water). Nonetheless, abnormal, damaged cells and proliferative cell growth in the ileum was documented in mice fed on Bt-toxin-transgenic potatoes [3]. In a related study, rats fed potatoes engineered to express the lectin

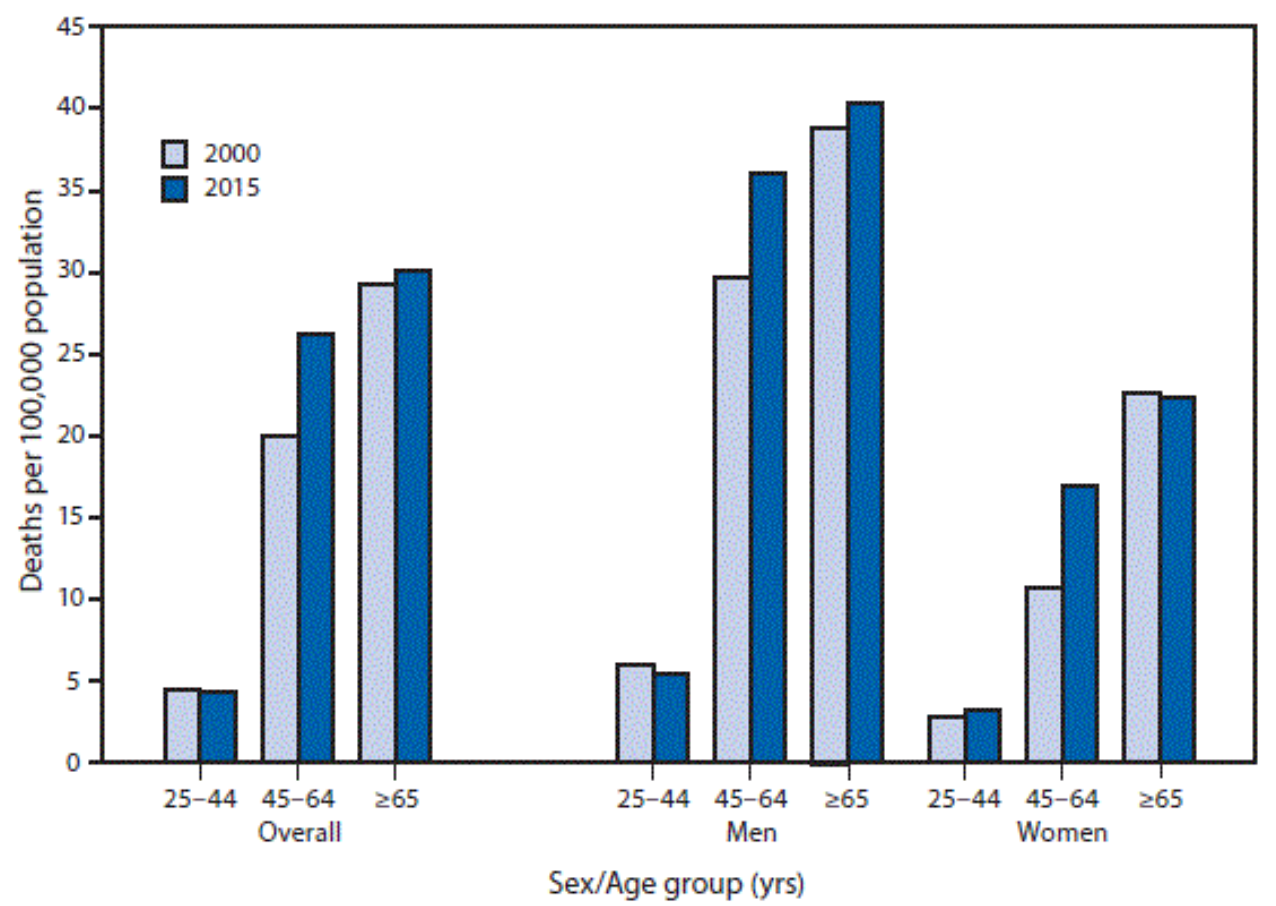

Figure 2. Centre for Disease Control and Prevention. Rates per 100,000 populations 
GNA showed proliferative activities of the gastric mucosa [4]. Cell proliferation is a precursor to malignancy and should be of a special concern with regard to supplementing diets with GMOs. Furthermore, the detailed study of Pusztai, et al. [5] documented both the organic and transgenic peas have the same nutritional value, however, recommended GM peas at the moderate levels of dietary inclusion for farm animal are not fit for human consumption. According to human gene therapy research; although the long-term consequences of the GM soy diet are not known, it "could lead to liver damage and consequently general toxemia [6]. Similarly, rats fed RRS showed hepatic structural changes [7].

Furthermore, extrapolation of data detailed below $(\mathbf{I}-\mathbf{I V})$ is of a major alarm as expected to disastrously reflect on the already expensive medical-care that is chewing the income of the middle-class and denied to the dispossessed segment of the society, in particular the homeless:

I- Reproductive Failures and Infant Mortality: The testicles of both mice and rats fed Roundup Ready soybeans showed dramatic changes. In rats, the organs became dark blue instead of pink [7]. In mice, young sperm cells were altered [8]. Embryos of GM soyfed mice also showed temporary changes in their DNA function, compared to those whose parents were fed non-GM soy [9]. We may entertain, in humans; matching lesions of this magnitude would culminate into flawed proportions of gender's specificity of newly born babies which is divined to evoke radical societal strains of specific individual's behaviorism.

II- Rats Fed GMOs Showed Higher Death Rates and Organ Damage: In the Flavr Savr tomato study, a note in the appendix indicated that 7 of 40 rats died within two weeks and were replaced [10]. In another study, chickens fed the herbicide tolerant "Liberty Link" corn died at twice the rate of those fed natural corn [11]. But in these two industry-funded studies, incidents of animals' mortality were dismissed without adequate explanation or follow-up.

III- In addition, pancreatic cells of mice fed Roundup Ready soy showed dramatic changes and produced significantly less digestive enzymes [12]. As well, rats fed GM potato showed enlarged pancreatic mass [10]. The logical extrapolation to this reporting is how the enlarged pancreatic mass would reflect on the healthy and already diabetic consumers? GM-fed animals showed lesions, toxicity, altered enzymatic production or inflammation of kidney [13]. GM potatoes caused slower growth in the brain of rats which may suggest with certainty a similar mechanistic pathway leading to eventual mental retardation in humans as a result of possible GMOs-induced facilitation of brain cells necrosis? Meticulously, a team of independent scientists re-analyzed the raw data in the three of Monsanto's 90-days rat feeding studies and concluded contradictory results, e.g., signs of toxicity in the liver and kidneys [14]. That is, Monsanto's supporting protocols are at best; an exercise in experimental irrelevancy and futility.

IV-Mice fed Bt and Roundup Ready Corn produced fewer and smaller litters [15]. In well-articulated contributions, beyond shadows of doubt, Irina Ermakova documented the risks of GMOs on mammalian health [16], viz.,

- Over a series of three experiments, 51.6 percent of the offspring from the GM-fed group died within the first three weeks, compared to 10 percent from the non-GM soy group, and 8.1 percent for non-soy controls.

- High pup mortality was characteristic of every litter from mothers fed the GM soy flour [16].

- The average size and weight of the GM-fed offspring was quite a bit smaller [16].
- In a preliminary study, the GM-fed offspring were unable to conceive [16].

\section{Discussion}

A review of the literature reveals the shallow and scientifically irrelevant and superficial argumentations in favour of the GMOs. Absolutely, the graceful 60 's with non-proprietary science and space exploration which thoroughly aimed at quenching humans' intellectualism to uninhibitedly delve into the unknown concomitantly rousing the Utopia of knowledge and tolerance was dramatically aborted by the military-industrial complex in favor of the academics of the profit-oriented science. That is the last corner stone of the joy of learning and the mental maximization into the polished comprehension of the mysteries of natural sciences has steadily disintegrated. Alas, universities' research facilities were dwarfed to the miniature size of medieval cages whose principal "the midget Alibaba" is contentedly serving the new master; the 21 century Academic Capitalism in lieu of the ancient tittle-tattle forty. That was the opportune circumstance to avail the in-vitro synthetic GMOs yields of laboratory bench Frankenstein experimentation to consumers without any relevant long term toxicological quests to ascertain its viability as safe nutrients. As expected, in lieu of impartial funding of universities' GMOs basic research to absolutely quantitate its biological safety; laypersons were helplessly swarmed with flimsy and mute scientific advertisement in favor of GMOs. These trailers were saturated with abundant ploys of flashy cellophane-wrapped commercials to GMOs benefits as the optimal product of human inventiveness of modern biotechnology contest to over population, shrinkage of green land, aridness, pesticides, herbicides pollution. That is GMOs are better quality food ingredients to consumers; in particular those of the third world countries. In this particular instance; we ought to reference the 50-years old Israeli saga of success, with the drop-wise application of RO desalinated sea water, the vast acreages of sandy deserts became a green paradise producing tropical fruits and all sorts of fresh vegetation. This protocol should be an example of humans' mental determination to extract natural resources from the impossible with the least damage to the environment.

Inaccurate pseudo-scientific publications and misleading marketing statements in favour of GMOs prevailed together with obvious bias in peer-review process and harassment of academic publications of scientists with opposing points of view. A glaring example is the alarming retraction of a published manuscript entitled "Long Term Toxicity of a Roundup Herbicide and a Roundup-Tolerant Genetically Modified Maize by G.-E. Seralini et al'. Although experimentations were well-designed and interpretations of data justifiably disfavoured GMOs as a viable dietary alternative, the article was unprofessionally retracted without offering solid scientific evidences that are rebuking to and negating the already attained conclusions.

Conclusions of an electronic circular written in a slums' language, entitled "Survey of Long Term GM Food Studies, Smilodon's Retreat" were in favour of the GMOs as dietary alternative to natural harvests. Alas, careful scrutiny crops a major mistrust of said claims as the integrity of methodology and the basic research of these trials are inadequate, absolutely. For example: the paragraph of said electronic circular entitled "Assessment of the Health Impact of GM Plant Diets in Long-Term and Multigenerational Animal Feeding Trials" is a superfluous nuisance, indeed. Bombastically, a literature review was claimed with a coerced conclusion in favour of GMOs; below in Italic:

We examined 12 long-term studies (ofmore than 90 days, up to 2 years in duration) and 12 multigenerational studies (from 2 to 5 generations). 
We referenced the 90-day studies on GM feed for which long-term or multigenerational study data were available. Many parameters have been examined using biochemical analyses, histological examination of specific organs, hematology and the detection of transgenic DNA. The statistical findings and methods have been considered from each study. Results from all the 24 studies do not suggest any health hazards and, in general, there were no statistically significant differences within parameters observed. However, some small differences were observed, though these fell within the normal variation range of the considered parameter and thus had no biological or toxicological significance. If required, a 90-day feeding study performed in rodents, according to the OECD Test Guideline, is generally considered sufficient in order to evaluate the health effects of GM feed. The studies reviewed present evidence to show that GM plants are nutritionally equivalent to their non-GM counterparts and can be safely used in food and feed.

First: considering the average life span of humans to range between 60 to 90 years, time-wise, the above claimed long-term studies up to 2 years is an error. The 12 multigenerational studies, from 2 to 5 generations, is an absolute ridicule as the agricultural communities could be traced to 8000 years ago when the Ancient Egyptians populated the two green banks of the River Nile. It will take more than 2 to 5 generations of experimental animals to sink the expected many debilitating effects of GMOs on humans and the environment.

Second: it would have been more professional if the statement "some small differences were observed" was qualified with detailed data to allow the reader the privilege to decide the significance of these small differences?

Ultimately, the $2 k+18$ laypersons are unceasingly hassled with ample, however suspicious, tolerance of the basic scientific community to the misplaced and reckless adventures of GMOs' manufacturers, shelf-availability of pharmaceuticals with well documented side effects, TV manipulations of consumers with diluted and quasi-scientific information (if scientific at all?), possible fraud in industry-sponsored research and ruling in favour of synthetic GMOs while FDA's top ranking posts are populated with individuals closely bound to GMOs
Industry. Illogically, while approaching the FDA claiming novelty of GMOs' produce, in the same breath Monsanto's misleading marketing strategy is bombarding consumers with the most ridiculous logic: our laboratory's genetic manipulation is no different from natural breeding taking place during 1000s of years ago!? The primitive depanneur chemistry of Monsanto's Safety Assessment of Yieldgard Rootwarm Corn, September 2003 is well manifested, viz., Tables A-1 to A-6 of said report. Monsanto paraded the same secondary school parameters pertaining to the quasi-chemistry of the ash content, humidity, amino acids, carbohydrates, total fat and protein for GMO and natural non-GMO yield! In this context, the new owner Bayer applied (An Application for approval for release of product of Soybean A2704-12 for supply or offer to supply NBB ref No. JBK(S) 602-1/1/7 applicant Bayer Co. (Malaysia Sdn. Bhd, Data submitted 23 August 2011)) with the least concern to the immediate or long term toxicity of GMOs to humans or environment. The said application of Bayer as well the cited 51 reference therein are void of solid confirmation to the Absolute Zero Probabilities of any horizontal insertion of GMOs edited moieties into consumers or bacterial gnome. This application turned the mountains of academic research into molehills of marketing manoeuvres.

Definitely, it takes more than the overly naive representation of basic analysis as per Bayer's application (pages 4 and 5) to release GMOs for consumption. Moreover, it is an absolute mockery to necessitate the release of GMOs as a biologically safe dietary additive or a substitute according to the statistics "if taste or texture is acceptable: on a scale from 1 to 5, Mark 1 for very satisfactory or 5 if not satisfactory"! What the taste or texture of the commodity has to do with biological safety? According to basic organic chemistry; it could be the same elementary analyses of two structurally different proteins and/ or glycoproteins, nonetheless either may display very different functionality with caustic consequences to consumer's health. Again for those who have ears and are willing to listen and understand: "what is the negative impact of the projected long term ingestion of these GM proteins/glycoproteins in terms of lateral/ horizontal insertion of these synthetic moieties into gut microbes, animal and/ or human genetic code? And what similar values of humidity and ash contents of GMOs versus organic counterparts have to do with toxicity of GMOs?"

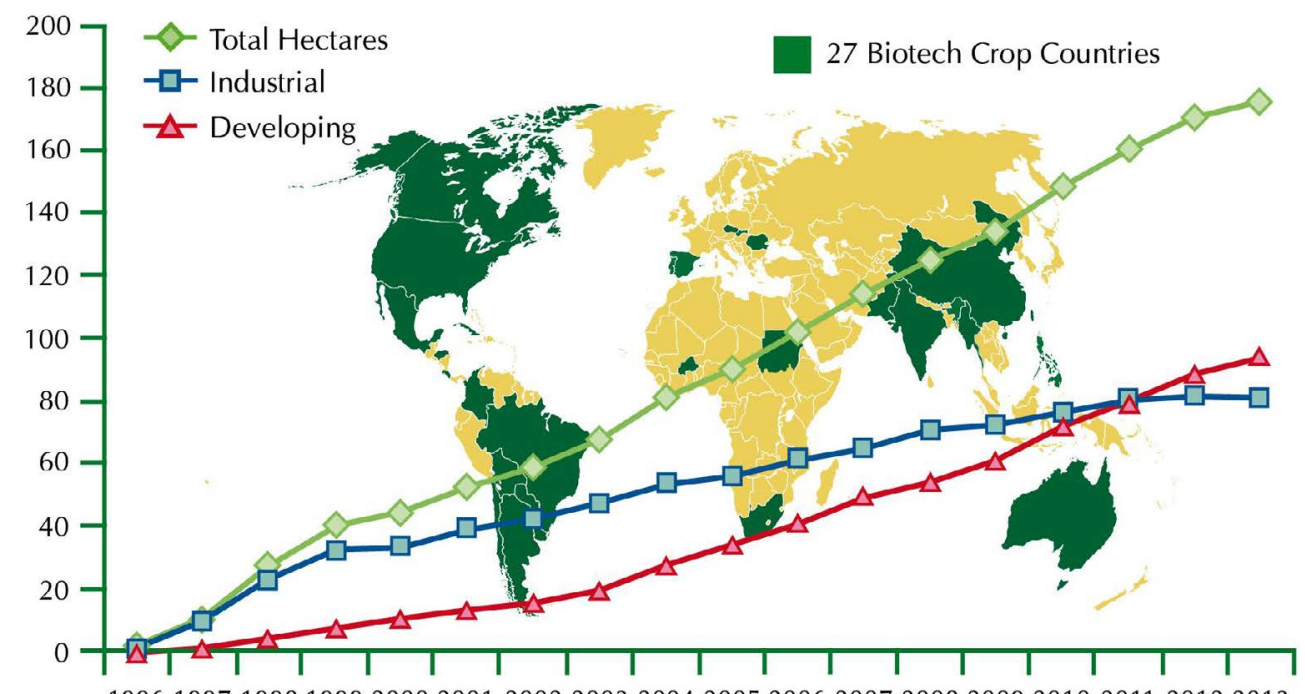

199619971998199920002001200220032004200520062007200820092010201120122013

A record 18 million farmers, in 27 countries, planted 175.2 million hectares (433 million acres) in 2013, a sustained increase of 3\% or 5 million hectares (12 million acres) over 2012.

Figure 3. UCDAVIS Animal Science http//:animalscience.ucdavis.edu/animalbiotech 
Shall we consider the map (Figure 3) and entertain the thought "The GMOs are the Reward of the Capitalism of Science to Obedient Regimes"? According to UN statistics, social ills classed Egypt the 9th nation worldwide with greater inequality, undoubtedly for obvious reasons Saudi Arabia should rank the first. These societal dilemmas ought to be settled according to tranquil means of reform and education. Nonetheless, the military-industry complex did not waste a minute to wave unnecessary inflammatory and theatrical critiques to their core values, i.e., dogma-synthesized societal issues. Concomitantly, camouflaged in the rhymed tunes as of manufacturing dishwashers to Liberation of Kuwait and the Arab Spring's rancid slogan of the 6 Million \$ Man "we can rebuild it, we have the technology ... we have the capabilities to do it", the GMOs are offered as the "salvation recipe" to world's third nations that are suffocating of shortages of harvests. Worse are the conclusions of scrutinizing the above map (Figure 3). Sudan, in terms of the available natural resources; namely, the abundance of both the green acreage and fresh water supply could reward the African content with fresh natural supply of daily bread. Meaninglessly, however most convenient to the multinationals, Sudan is the largest African state to allow GMOs. Regardless the ICC issued a warrant to arrest Sudan's President al-Bashir on the account of genocidal murders against humanity, for his obedience to the GMO multinationals, al-Bashir was winked safety. It is perplexing, not only he is shuttling freely in between various cities in the Middle East, but exaggerated his gratitude as volunteered to tighten the grip on Egypt to follow suit, i.e., to join the GMOs club. As an extra venomous supporting breath in this precarious time of the Middle East pregnant with chronic political instability, Sudan is supporting Ethiopia's peace threatening adventure of building the Renaissance Dam. When fully operational, this Dam is claimed to starve Egypt of water. Most recently, the immature Sudanese politicians openly boasted the slogans of starving Egypt of the Nile's water and declared war on Egypt! Most likely, the Sudanese support of the Ethiopian Renaissance Dam is a political manipulation to dilute the assuredly negative impact of scientific data published by the local Egyptian scientists on the decision making-Political Bureau: Rats fed the Egyptian GM corn (MON810: Ajeeb YG (MON810; literally Wonderful YG!!!)) developed "serious damage to the surface mucous membranes of the jejunum. Rats fed MON810 Wonderful YG showed damage to some areas of the villi, crypts were disrupted and blood vessels were congested with signs of white blood cell infiltration, as well. Other signs of damage included increased shedding of mucosal cells, increased numbers of mucoussecreting goblet cells, and higher rates of division of cells lining the crypts."

In this surreal context, as a cover-up to the obvious plot, preposterously the ICC reported the Kingdom of Jordan to the U.N. Security Council on the account of failing to arrest al-Bashir while visiting Jordan. This measure is expected to destabilize Jordan in face of terrorism which is wrecking every corner in the world. Therefore, it is our contention: political maneuvering, rather than substantial experimental argumentations in favour of GMOs, is the preferred coercion policy to export this particularly manufactured and doubtful commodity to the third world nations. Although a recent reporting GMO Status - Sudan Rome / 2June 2015 recognised the Agricultural Sector as the Country's Mainstay and discussed agricultural constraints, it failed miserably to discuss urgent priorities, e.g., the impact of political corruption on the rampant poverty in Sudan with possible precipitation of near future famines harvesting the lives of millions of children. Political corruption in Sudan made it impossible for the country's technocrats (if there is any?) to ease the well rooted poverty and the ingrained laziness that is well galvanized into the fabric of said lay-public. They willingly failed, or most likely were unable, to take advantage of the abundance of both water and green fields availed as early as of the 1960s in Sudan in response to the massive accumulation of fresh water, soil and minerals in Nasser's lake behind the Egyptian Aswan High Dam.

On the account of the two green banks of the River Nile, the most fertile area on the planet, which availed yearly rich vegetation to the Ancient Egyptians, the first human civilization sprang and lasted for 8000 years and left more than $75 \%$ of the world's ancient artefacts in the land of Egypt. The hurriedly built Aswan High Dam was supposed to have modernized and availed abundant vegetation to Egypt and Sudan. Instead, restricting the flow of the River Nile's fresh water has proportionally limited the supply of natural nitrate fertilizer and organic materials' sediments into Egypt's two green stretches. This necessitated the waste of about one-third of the dam's electric output to fertilizers production. Moreover, the dam is silting up and may cease to serve any useful purpose within the next few centuries. In addition, the salinity of the Mediterranean Sea is on the rise as a result of slow influx of the River Nile's fresh water which has drastically changed its echo system and the quality and quantity of fish harvest. In this context, the French alternative, submitted to the Egyptian authorities at the time, suggested building several smaller Dams at calculated distances along the River Nile within Egypt proper. This proposal could have enormously diluted the problems cited above of the massively built High Aswan Dam in one location; Upper Egypt. Unfortunately, the decision was taken by the ignoramus officers of 1952-coup. Most likely, the colossal volume of the High Aswan Dam aroused and resonated well with their instinctive self-esteem rather than the scientifically appropriate conceptualization of environmental sustainability that was well advocated in the French alternative. Together with the influx of the imported dogmatic long sermons, the latest census of 2017 revealed the Egyptian population abruptly increased from the 25 million of the 1950 to the current 102 million. Why not? The circulating sermons are portraying the Omnipotent of having an endless and plentiful supply of water and daily bread for His believers on earth and in Heavens. One of the most damaging outcomes to these sermons is the enormity of the divorced females below 16-years of age supporting 2-3 children! At what age these miserable female children were married? The obvious outcome is the demolition of the basic fabric of the Egyptian society together with placing Egypt in a total economic collapse with serious shortage in basic ingredients of food supply. Of course, we are not shy to claim, wisely managing these societal problems and the shrinking resources according to Israeli technologies, but not adopting the intoxicants GMOs for cultivation, would restore abundant daily sustenance to the populace. The origin of insufficiency of Agricultural harvests in most of the underdeveloped third world countries is not necessarily the shortage of water and/ or green land but rather corrupt individuals at the helm of the nation (Sudan above). As well, tribe's unequal distribution of extracted wealth (oil?) together with the melancholy of militaristic dogmatism, e.g., Arab Spring States of Iraq, Syria, Yemen, most recently the Kurdish Spring, etc.

Rather than focusing on the physical significance of whatever basic scientific data is available to benefit the public, biotechnology industry was allowed to dominate the US federal regulatory bodies, e.g., the FDA. Concomitantly, selection of the so-called scientific experts arbitrating on the viability of transgenic harvests was monopolized by cronies with vested interest in marketing GMOs with prompt and lucrative gains. Thus, hasty commercialization of GMOs was favoured together with diluting the impact of the many opposing research findings pertaining to GMOs intoxication of both humans and the environment. Besides the reliance of universities' $\mathrm{R} \& \mathrm{D}$ funding on private biotechnology 
industry with specific agendas rather than public support hatched the pseudo-science of imposed commercials of pharmaceuticals, e.g., rather than Camelot's "Do not ask what your country can do for you, but what you can do for your country", the motive deteriorated to "ask your doctor if ...(name of the drug)... is suitable for you or "do not take ...(name of drug)... without prior consultation with your doctor or if you are suffering from ... " and food additives. Most likely, these chemicals are the causative factor behind the recent plagues of de novo allergies and immunes' deficiencies.

The puritanism of open scientific debates is defined as the option to trail data of basic research irrespective of the \$-profitability of the conclusions have delivered to the concerned scientists. This distinct morality of physical organic chemists, Sir Prof. C.K. Ingold and Prof. Youssef Iskander, guaranteed the impartiality of scientists, that is to desist the $\$$-value of their conclusion. Ingeniously, scientific conferences were arranged to freely debate scientific threads, ultimately the sanctity of basic research as defined above was briefly retained. Nevertheless, with the advent of biotechnology industries, the basic essence of scientific research was obliterated, i.e., purpose and design of experimentations and interpretation of results therefrom must always be subject to the critical inquisition of the necessity of academic capitalism and commercialization. For example, the 1980 Bayh-Dole Act of the US congress gestured the intrusion of political bureaucrats into the very intellectual dynamics of scientific inquiries. This measure did hasten the exponential decadence of the main purpose and focus of academic research. Alas, the general trend of the loss of academic values and direction became not a very particular specificity of science as metastasised to become a major attribute of a general societal malaise. This ethical fatigue did accurately reciprocate the current Western melancholic dualism. For example, admitting the least educated with barely any academic distinctness save their narrow dogmatism, Tariq Ramadan and Nader Bakar, to the most prestigious universities of Oxford and Harvard respectively. Therefore, it is not surprising the least, USDA disbursed 1.8 billion \$ for research in biotechnology, only an error fraction of that sum (18 million) was allocated to dwell into the adverse effects of these biologically active ingredients. Equally, the recent 500 million $\$$ research grant from BP to the university of California precipitated a major stir. Helplessly, universities became dependent on private industry to sponsor academic research [16].

So far, the principal GM produce is an amazing jungle of uncertainties, toxicity and pollution to humans' domain and environmental topography respectively. The spectrum of manufactured GMOs included a wide range of produce (i) herbicide and insecticideresistant soybeans, corn, cotton canola, sweet potato resistant to a virus that could destroy most of the African harvest!, (ii) rice with increased iron and vitamins claimed to alleviate chronic malnutrition in Asian countries!, (iii) a variety of plants that is able to survive weather extremes and most interestingly (iv) the expected billion dollars business is the GM bananas engineered to produce various human vaccines against infectious diseases, e.g., hepatitis B, (v) fish that mature more quickly, fruit, (vi) nut trees that yield years earlier and (vii) plants that produce new plastics with unique properties. What are the expected toxicity of these products to humans' integrity and environment?

A GMO supporting trial was carried out on three groups of aged rats (10 each for 455 days) were fed ad libitum (i) organic soy, (ii) GM soy to which three bacterial genes were inserted, and (iii) a control on casein. This experimentation revealed; the weight of rats fed GM soy was the same as that fed organic soy, however both were higher than the control. Protein intake was similar for the organic and GM soy fed rats, but was significantly lower $(p<0.0005)$ than the control animals. It was further reported; in terms of the growth rate of animals, albumin levels and total levels of serum protein, the three variables were comparable for all groups. Assuming, experimentations were carried out on same age rats with closely comparable weights, it is very feasible to suggest $\boldsymbol{a}$ slower metabolic activities for both the organic and GM soy fed models vis-à-vis control rats? Surprisingly, according to the hematocrit $(\mathrm{p}<0.04)$ and hemoglobin $(\mathrm{p}<0.03)$ data; authors suggested the protein quality of soy was similar to the standard protein casein in terms of growth promotion but not hematological indicators [17]. A grave disadvantage to this trial is the very possibility; the protein constituent of the control's feed, casein, was similarly polluted with GM rBGH. Furthermore, the conclusion of animals fed GM or

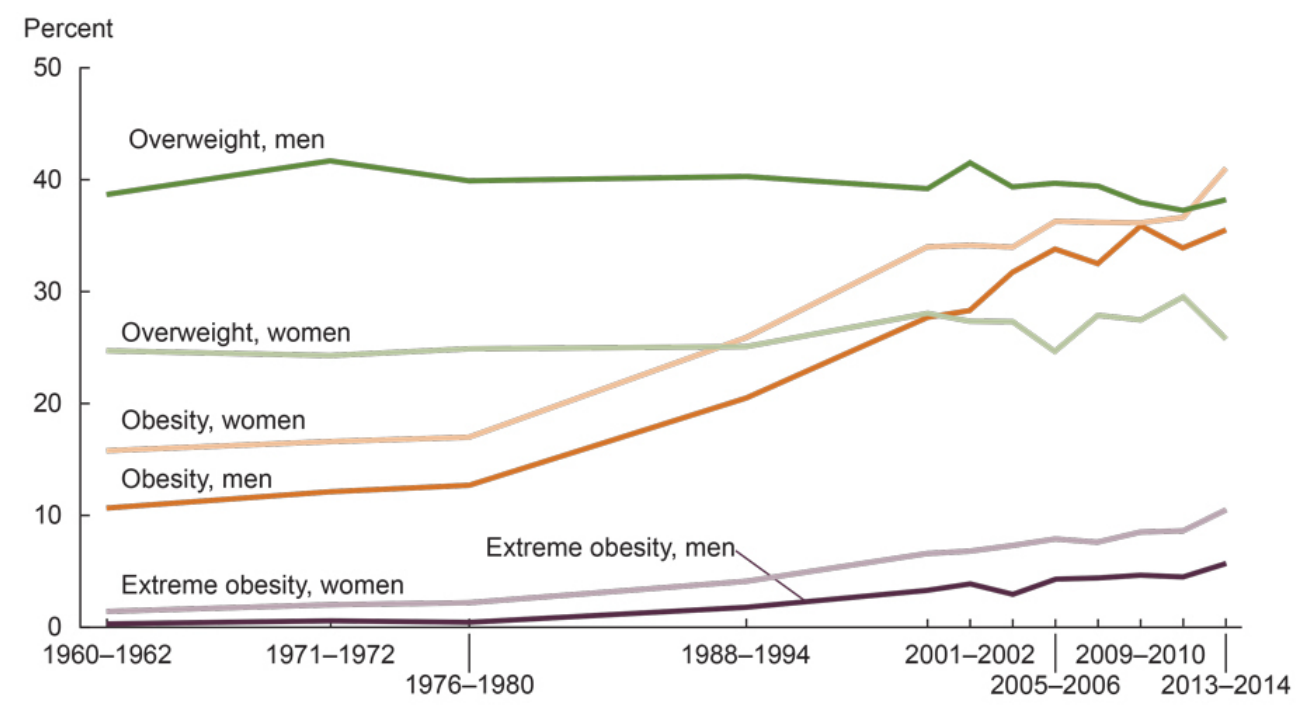

NOTES: Age-adjusted by the direct method to the year 2000 U.S. Census Bureau estimates using age groups $20-39,40-59$, and $60-74$. Overweight is body mass index (BMI) of $25 \mathrm{~kg} / \mathrm{m}^{2}$ or greater but less than $30 \mathrm{~kg} / \mathrm{m}^{2}$; obesity is BMI greater than or equal to 30 ; and extreme obesity is BMI greater than or equal to 40 . Pregnant females were excluded from the analysis.

SOURCES: NCHS, National Health Examination Survey and National Health and Nutrition Examination Surveys.

Figure 4. Trends in adults over weight, obesity and extreme obesity among men and women aged 20-74: United States, 1960-962 trough 2013-2014 
organic soy had lower metabolic activity vis-à-vis control rats suggests both GM and organic soybean's chow-diets are equally polluted, thus reacted similarly with the animals' microbiome?

Moreover, it is a scientific ridicule to extrapolate conclusions of 455 days experiment carried on aged rat model fed GM soy meal to humans whose life expectancy range 70-90 years, indeed. Worse, it is a scientific naïvety to consider the depanneur parameters such as animals' weight, protein intake, growth rate, level of serum protein as a conclusive pointer to avail GMOs for safe consumption by animals and humans. In this regard, full diagnosis at the molecular level, kidney function, hepatic efficiency, neurological integrity of animal model for at least 30 - 50 generations with full knowledge of the source of animals' diet, specifically the control chow, are required to give some credence to conclusions therefrom. Furthermore, scrutinizing details of Figure 4 cast heavy doubts on reasons supporting GMOs research.

In a related study, controls and 14\% GM-soybean diet-expressing CP4EPSPS gene conferring high level tolerance to glyphosate, fed mice were likewise affected by aging [18]. Comparably, long term feeding on GM soybean (1-24 months) did not induce structural alterations in duodenal and colonic epithelium or in coliform population. Nonetheless, histochemical scrutiny disclosed significant dietrelated changes in amounts of the duodenum's mucin. In particular, the percentage of villous area occupied by acidic and sulpho-mucin granules decreased from controls to GM-fed animals, whereas neutral mucins did not change [18]. The relevant question is what the physical significance of the decreased proportions of charged mucinous glycoproteins in duodenum of animals fed GM soy? Different structural composition (functions?) of charged mucinous glycoproteins versus neutral counterparts in protecting the different layers of guts against acidic environment?

In a long-term feeding of genetically modified corn (MON810) to dairy cow, it was claimed all collected blood, milk and urine samples were free of recombinant DNA and protein. Although, crylAb gene was not detected in any faecal sample, the immuno-reactive fragments of the CrylAb protein were detected in faeces from all cows fed transgenic feed. Accordingly authors came to conclude, milk of dairy cows fed genetically modified corn for 25 months should be classified not different from milk of cows fed non-transgenic corn [19]. Obviously, experimentations would warrant this hasty conclusion if were carried out on multi-generations cows with close attention to the integrity of the genetic code as say of the 6th generation animals provided absolute zero detection of these in-vitro manipulated GMOs genes in the bovine's bacterial microbiome.

Biochemical and histopathological investigation in a three generation rats fed GM Bt corn boiled down to the histopathology of experimental models' stomach, duodenum, liver and kidney's tissues. The average diameter of glomeruli, thickness of renal cortex and glomerular volume were calculated, as well. Basic serum diagnostics, e.g., creatinine, uric acid, urea nitrogen, total protein, albumin, globulin, SGOT, ALAT, Alk Phos, GGT, CK and amylase were assayed. According to this particular set of data, no significant differences were found in terms of relative organ weights of rats within groups but there were some minimal histopathological changes in liver and kidney which according to authors are not of major concern. No changes in liver or kidney enzymatic profiles were reported. Thus authors concluded; rats fed GM Bt corn showed neither changes in hepatic or renal functions. However, slight reduction in albumin/globulin ratio in rats fed 33\% MON810 GM corn was observed [20]. Irrevocably, these over simplified protocols of the depanneur chemistry do not lend any support to unequivocal indications pertaining to the DNA-integrity of various tissue proteins of various organs of individual animals fed on MON810 Bt corn.

Results of a long ten generation term feeding growing and laying quails with of Bt-corn were driven to conclude the same naïve interpretation with the conclusion: no significant influence on health and performance of quails nor did it affect DNA-transfer and quality of meat and eggs of quails compared with the isogenic counterpart [21].

A seven month trial feeding Atlantic salmon (Salmo salar L., $40 \mathrm{~g}$ going through the parr-smolt transformation) on RRS soy was carried out. Both non-GM and GM diets were compositionally similar in all analysed nutrients. Performance and health of the fish were assessed in terms of growth, body composition, organ development, haematological parameters, clinical plasma chemistry and lysozyme levels, with samples collected both in the freshwater and seawater stages. Although, plasma triacylglycerol levels were higher in the GM group, a specific difference was larger around the time of seawater transfer compared to later samplings, there were no differences in the total growth during the trial. Typically, the overall conclusion was: the observed effects of feeding Atlantic salmon with GM soy at a $25 \%$ inclusion level were minor, and lack of consistency with previous studies suggests that they might be caused by variations in the soy strains rather than the genetic modification per se [22].

Gene transfer studies in human volunteers [23] To start with, human microbiome's metabolic activity is a rate-limiting step in control of individuals' physiology and health parameters. As of January 2009, a trial of feeding GM soy to a compromised human model was carried out to scan if DNA of GM soy was inserted into human-microbiome's bacteria [23]. For earlier medical reasons these volunteers had their large intestines removed. It is our contention; there is no scientific significance whatsoever except the absolute ridicule to a set of data carried out on 7 compromised volunteers to validate similar metabolic pathways to the current world's population of 7.6 billion. Moreover, 3 of the 7 volunteers had low frequency gene transfer from GM soya into the microflora of the small bowel before the start of the feeding experiment. The proportion of transgene that survived passage through the small bowel varied among individuals with a maximal of $3.7 \%$ recovered at the stoma of one individual, i.e., transgene did not survive passage through the intact human's gastrointestinal tract. Thus, authors concluded the gene transfer did not occur during the course of said experiment as this low-frequency transfer did not increase after the consumption of GM soy.

\section{Conclusion}

As reviewed above, the issue of genetically modified crops and food is rather a controversial and noxious one to consumers' health and sustenance of the environment. As organic safety tests of GMOs are either purposely disregarded or in its infancy, it is deemed essential to carry out an adequate long term basic scientific studies pertaining to their health risks, e.g. probable precipitation of infertility, de novo spectrum of mutated diseases of the currently well recognizable cardiovascular, gastrointestinal, pancreatic ailments, allergies, kidney and hepatic insufficiencies, maladies, deformed neural integrity, etc. As well, it is very feasible recycling by-products of GMOs' consumption may lead to irrevocable intoxications of general environment and available natural resources. To start with, the issue that is most determinable to the integrity of humans' health, i.e., microbiomes' resemblance to healthy individuals and probable transgenic transfer of GM plant/ and or animal's manipulated moieties to human genome 
should be academically and adequately addressed and searched in a long term trials together with absolute unbiased funding. Concomitantly, to abort the slightest possibility of side effects, an absolute ban on free market circulation of GM products should be in effect until these search data are published, thoroughly and solely discussed and debated by academics and scientist who never entertained the slightest contacts or binding interest as research funds to GMOs manufacturers.

The absolute ridicule is the epic of Golden Rice [1]. Golden rice is a variety of rice that is GM to biosynthesize, $\beta$-carotene, a precursor of vitamin $\mathrm{A}$, in the edible parts of rice. It was heralded as the savior produce in locations with vitamin A deficiency; especially vitamin A deficiency is estimated to kill 670,000 children under the age of 5 each year. Should the main concern of manufacturing Golden Rice is combating the astounding third world infants' mortality, it would have been financially, logistically and administratively much easier if tablets of vitamin A are non-profitably distributed for free among the destitute children as millions are already dying while waiting for the commercialization of an environmentally GM-suspect produce? To overcome the plague of famines in Africa, these humanitarian ventures of the GMOs multinational may also entertain introducing GM corn that is genetically edited to yield a harvest of $70 \%$ bovine proteins, $10 \%$ polyunsaturated triacylglycerols of, the highly unsaturated and nutritious, grape seed oil, 15\% carbohydrates and 5\% minerals and vitamins. Why not? That would be more nourishing to the thirdworld populace that is predominantly disadvantaged? Needless to say, a hypothetical product carrying three genetic modifications would require detailed biomedical elaboration to confirm its biosafety and improve it, if necessary. Should this hypothetical corn seed of the dispossessed score biomedical viability for general consumption, then naturally, the next humanitarian target would be the Golden Rich Corn.

The latest adventure is to produce hepatitis and other vaccines GMO banana? Although, scientifically the concept is positively adventurous and sound as products may minimise incidents of tropical ailments among the disadvantaged, however according to earlier experience; it could hasten catastrophes as with vaccines prepared in African monkeys! Absolutely, this particular issue should be treated with the utmost possible circumspection. According to D. Horowitz conclusion below in italic [1], viz.,

By 1993, I had become the chief investigator of the murder theory in the Florida dental AIDS tragedy in the case involving Kimberly Bergalis and her dentist David Acer who was blamed for her infection. While investigating Dr. Acer's belief that the AIDS virus was man-made, $I$ reviewed supporting documentation including a most disturbing document from the Department of Defense (DOD) appropriations request for $\$ 10$ million for the development The incriminating Congressional hearing testimony was sent to Dr. Acer by Robert Strecker, M.D.,Ph.D., the first American authority to investigate the man-made theory of AIDS's origin.

I thus began to investigate this document and Dr. Strecker's World Health Organization theory that AIDS and its causative agent the human immunodeficiency virus (HIV-1) was man-made and intentionally transmitted via contaminated vaccines to gay men in New York and Blacks in Central Africa. During the next three years I reviewed more than 2500 pertinent scientific papers and government documents. I was astonished to learn that there was no direct scientific evidence for the natural evolution of HIV-1 from monkeys to man. On the contrary, a large body of evidence that I eventually documented in the book "Emerging Viruses: AIDS \& Ebola - Nature, Accident or Intentional?" (Tetrahedron, LLC, 1997) raised the distinct possibility that HIV-1, and its relatives $H I V-2$ and the simian immunodeficiency viruses (SIVs), more likely evolved as a result of National Cancer Institute (NCI) and $D O D$ cancer virus and/or biological weapons experiments.

Historically, the simultaneous emergence of AIDS in Central Africa and in New York City during the late 1970s closely followed a period of major advances in molecular recombinant biology and retrovirology in the genetic engineering of mutant viruses that acted slowly to produce immune-system decay and an array of outcomes including the development of infectious diseases and traditionally rare cancers.

For the purpose of attaining a prompt and a maximal \$-return on their Frankenstein transgenesis ploys; it is the contention of many scientists and nutritionists: the GMOs' high ranking officers within the FDA manipulated the agency as not to label GMO products. $\dot{A} \boldsymbol{l} \boldsymbol{a}$ Ghandi, Peaceful however, grandiose the Salt March, the producers of organic and natural crops would undoubtedly benefit consumers' health and societal cohesiveness should they clearly mark their products and harvests "Certified None-GMOs". It this context, Cisgenesis and Intragenesis which were proposed as a viable alternative to Transgenesis [24] is equally risky to human health and sustenance of nature. In said absolute peaceful gesture as expensive as the printing green ink, producers of natural food commodities could spare humans and the environment the negative consequences of the GMOs ploys should their crops are marked None-GMOs.

In the final analysis, the collapse of the Roman Empire brought

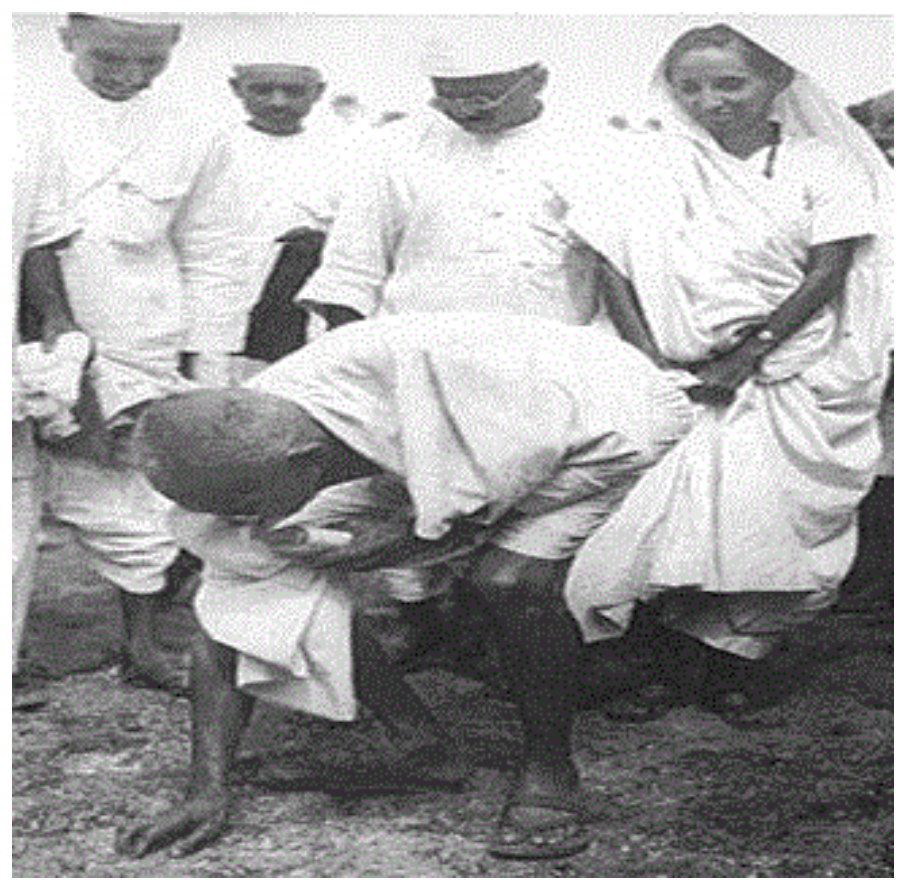

havoc and major long range disorders in corresponding protectorates which culminated into (i) the 641 purge of the civilizations of Egypt, Syria, Iraq, Persia and (ii) the May 29th, 1543 fall of Constantinople. The main feature of these events was the intellectual bankruptcy of human endeavours which was further maximized during the years of the inquisition. Nonetheless, it took the revolt of October $31^{\text {st }} 1517$ to reverse this declining trend. By comparison the $\$$ and the gluttony of few multinationals will most likely precipitate the devolution of human genome and intellectualism together with nature's irrevocable pollution, without any feasible 1517-mechanisms of decontaminations. 
The most challenging thesis to the GMOs' manufacturers is: how the tightly secured environmental cycle consumption, growth and death will adapt to GMOs targets and insects once an innate resistance is manifested? Hypothetically, according to the orthodox bible of pharmaceutical multinationals, the in-vitro synthesis of novel GMOs to ancient GMOs? That is the new lucrative scientific ventures of the biotechnology multinationals as assured of 7 billion consumers of three daily meals. No more wars as nations and its populace are tamed according to their daily bread: "Control food and you control both nations and the people"

Considering the current fragility of North American individuals, Figures 1-4, and the political turmoil in the Middle East which has spelled disastrous events worldwide, it is most prudent to place a complete halt on releasing GMO products to consumers until basic organic chemistry search decrees in its favour. In this context, basic scientists with their mathematical precision of thermodynamics and steady behaviourism according to Le Chatelier's laws of equilibrium, ought to advance to key political posts to arrest this reckless gamble with the Inviolability of human genome and environmental Invulnerability. In conclusion; we are ardent believers in ML King's "An individual who breaks a law that conscience tells him is unjust, and who willingly accepts the penalty of imprisonment in order to arouse the conscience of the community over its injustice, is in reality expressing the highest respect for the law [25]". Fittingly, the execution of Julius and Ethel Rosenberg and the imprisonment of Dr. Klaus Fuchs are a total waste of human endeavour towards a safe, just and a balanced world. The motive of these individuals is the same as that of Petros; the fisherman. To this end, laboratory manuals of basic scientists would manage predicaments without a shade of bias-characteristics of a maitre d'hôtel turned a politician at a redundant old age or his predecessor's succumbing to the adoration (the Amsterdam Syndrome): of the pharmaceutical multinationals masters while approving the stem cell research as ancestors were in the cotton fields. The current reckless and hasty disembowelment of natural resources and acute shortages of a steady supply of sustenance's for individuals of the 3rd world were precipitated, in part, by the unquenchable desire of the militaryindustry complex for supremacy, e.g., transhumanism, geoengineeringinduction of earth tremors, tsunamis, etc. Together with, the chronic ineptness of the current midgets on deciding learned leaps into more civilized options does not bode well at all for a safe foreseeable future for all humans. In this context, organic chemists are the most amenable individuals to perceptively satiate the vacuum created by the absence of political pillars such as JF Kennedy, RF Kennedy, Rene Levesque and PE Trudeau, assuming they are willing to relinquish the comfort zones of their laboratories. Our hypothesis is: annals of basic scientists refute a Mojito room service at a bankrupt hotel nor would it concede to the most inflammatory orations, e.g., the rocket man, short and fat, mad man, etc., at an international league.

In a step that could change the definition of death, a Yale University team, Nenad Sestan et al., have restored circulation to the brains of more than 100 decapitated pigs (A) and kept the reanimated organs alive for $\sim 36$ hours. Hog brains were obtained from a slaughterhouse, circulation was restored using a system of pumps, heaters, and bags of artificial blood warmed to body temperature. This protocol prompted billions of cells in the brain to resume biological integrity. However, animals did not regain consciousness [26]. It was suggested; this experiment will have a big impact in the medical field. The team further elaborated; although pigs did not regain consciousness, it is possible to restore awareness and argued for the prospect of keeping the human brains alive outside the body. Nonetheless, according to ethics, Benjamin Curtis questioned the relevancy of the experiment and labelled it "it could lead to humans enduring living hell". Even if your conscious brain were kept alive after your body had died, you would have to spend the foreseeable future as a disembodied brain in a bucket, locked away inside your own mind without access to the sense that allow us to experience and interact with the world. Even with fully functional body, immortality would be tedious. It would be a living-hell without contact to external reality [26].

Sadly, however entertaining, is relating the mental status of the dogmatically hallucinating Middle Easterners $\boldsymbol{v i s}$-à-vis Western-ethical standards:

In a crude linguistic manipulation of facts and to market gender inequality, a well-known cleric tried to blunt the Egyptian secular opposition to the disgrace of female genital mutilation, i.e., circumcision. He claimed, it is inaccurate to call the removal of the clitoral hood and clitoral glans a circumcision. It is rather a surgical minimization of these parts to help females manage sexual arousal and stimulation upon encountering males! We read that as a typical Middle Eastern impotent males' fear of female sexuality.

In Egypt, a 5-years old preparatory school boy (B) was taken to court for trial on the account of kissing a female pupil in his class!

In a saluting gesture to nations of competing athletes, a beer bottling facility printed the flag of these nations on the crown (C). For obvious reasons, the beer bottling facility had to openly apologize for printing the Saudi flag on the crown of beer bottles (C).

Geoengineering is the deliberate large-scale intervention in the Earth's natural systems to counteract climatic changes. The topic in-

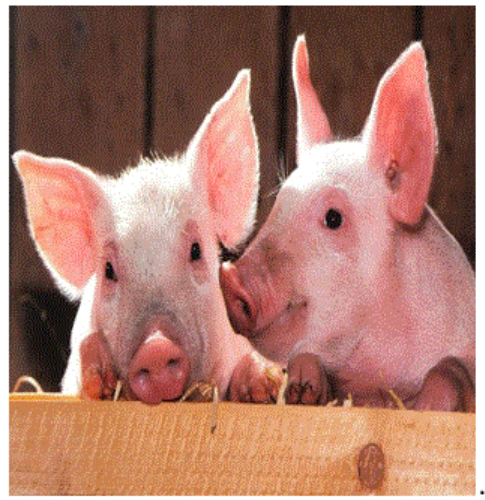

(A)

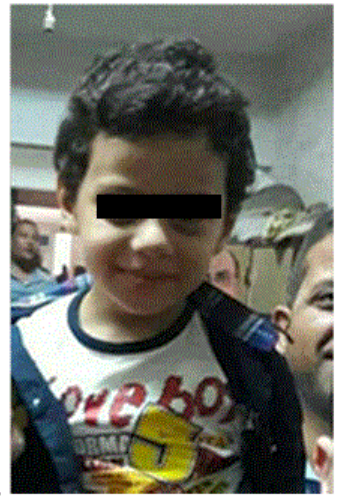

(B)

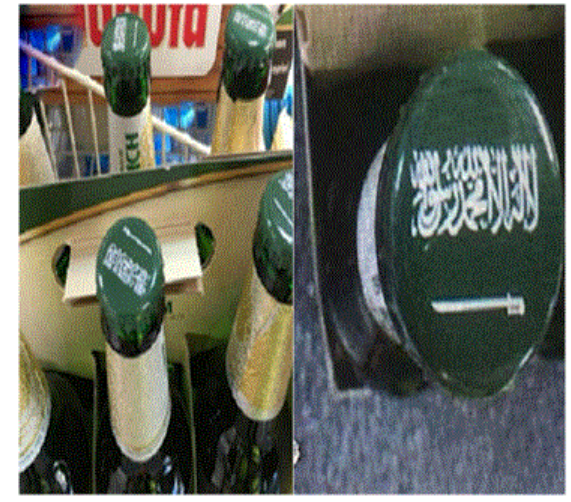

(C) 
cludes (a) Solar Radiation Management (SRM) or Solar Geoengineering and (b) Carbon Dioxide Removal (CDR) or Carbon Geoengineering. Although, officials innocently argued for more geoengineering studies, the narcissism of the military-industry complex could detour geoengineering to its ends, localized tsunamis, earthquakes, etc., in locations of choice. That is Are microwave transmission weapons of mass destruction being used to trigger catastrophic earthquakes? However, the education and intellectually-void clerics see earthquakes and other natural disasters as God's call to punish the infidels! And if a natural disaster took place in a community of believers, it could be indicative of a group of believers went astray and remorse is deemed essential to evade further punishments!

\section{Dedication}

To Naguib Sawiris, the philanthropist who indisputably registered his resources and social status in favor of the dispossessed. Patience of the Managing Editor is most appreciated.

\section{References}

1. Service RF (2017) Spinning spider silk into startup gold, Science, October 18. 2017; Le Page M (2016) First evidence that GM mosquitoes reduce disease, New Scientist. 15 July; Horowitz L. (2002). AIDS: Genocidal Germ for a New World Order? Origins of AIDS.com. and Kava R (2016) Potential benefits of golden rice would be greatest for the poorest, American Council on Science and Health September 21. Langridge WHR (2000) Edible Vaccines. Scientific American 66-71.

2. Dona A, Arvanitoyannis IS (2009) Health Risks of Genetically Modified Foods. Critical Reviews in Food Science and Nutrition 49: 164-175.

3. Fares NH, El-Sayed AK (1998) Fine Structural Changes in the Ileum of Mice Fed on Endotoxin-Treated Potatoes and Transgenic Potatoes. Natural Toxins 6: 219-233.

4. Ewen SWB, Pusztai A (1999) Effect of diets containing genetically modified potatoes expressing Galanthus nivalis lectin on rat small intestine. The Lancet 354: 1353-1354.

5. Pusztai A (2005) Facts Behind the GM Pea Controversy: Epigenetics, Transgenic Plants and Risk Assessment. Proceedings of the Conference, Frankfurt am Main, Germany: Literaturhaus, pp: $37-40$

6. Smith MF (2007) Genetic Roulette: The Documented Health Risks of Genetically Engineered Foods, Yes! Books, Fairfield, IA USA.

7. Ermakova I (2007) Experimental Evidence of GMO Hazards. Presentation at Scientists for a GM Free Europe, EU Parliament, Brussels, June 12, 2007.

8. Vecchio L, Cisterna B, Malatesta M. et al. (2004) Ultrastructural Analysis of Testes from Mice Fed on Genetically Modified Soybean. Eur J of Histochemi 48: 448-454.

9. Oliveri, et al. (2006) Temporary Depression of Transcription in Mouse Pre-implantation Embryos from Mice Fed on Genetically Modified Soybean. 48th Symposium of the Society for Histochemistry, Lake Maggiore (Italy), September, pp: 7-10.
10. Pusztai A (203) Can Science Give Us the Tools for Recognizing Possible Health Risks for GM Food? Nutrition and Health 16: 73-84.

11. Leeson S (1996) The Effect of Glufosinate Resistant Corn on Growth of Male Broiler Chickens. Department of Animal and Poultry Sciences, University of Guelph, Report No. A56379, July 12.

12. Malatesta M, Caporaloni C, Rossi R, Battistelli S, Rocchi MB, et al. (2002) Ultrastructural Analysis of Pancreatic Acinar Cells from Mice Fed on genetically modified Soybean. J Anat 201: 409-415. [Crossref]

13. Tudisco R, Lombardi P, Bovera F, d`Angelo D, Cutrignelli MI, et al. (2006) Genetically Modified Soya Bean in Rabbit Feeding: Detection of DNA Fragments and Evaluation of Metabolic Effects by Enzymatic Analysis. Animal Science 82: 193-199.

14. de Vendômois JS, Roullier F, Cellier D, Séralini GE (2009) A Comparison of the Effects of Three GM Corn Varieties on Mammalian Health. Int J Biol Sci 5: 706-726.

15. Velimirov A, Binter C, (2008) Biological effects of transgenic maize NK603xMON810 fed in long term reproduction studies in mice. Forschungsberichte der Sektion IV, Band 3: $1-105$

16. Ermakova IV (2006) "Genetically Modified Organisms and Biological Risks," Proceedings of International Disaster Reduction Conference (IDRC) Davos, Switzerland August 27th: 168-172.

17. Daleprane JB, Feijo TS, Boaventura GT (2009) Organic and genetically modified soybean diets; consequences in growth and in hematological indicators of aged rats. Plant Foods Hum Nutr 64: 1-5.

18. Battistelli S, Citterio B, Baldelli B (2010) Histochemical and morpho-metrical study of mouse intestine epithelium after a long term diet containing genetically modified soybean. Eur J Histochem 54: 154-157.

19. Guertler P, Paul V, Steinke K (2010) Long-term feeding of genetically modified corn (MON810) - Fate of cry1Ab DNA and recombinant protein during the metabolism of the dairy cow. Livestock Science 131: 250-259.

20. Kilic A, Akay MT (2008) A three generation study with genetically modified Bt corn in rats: Biochemical and histopathological investigation. Food Chem Toxicology 46: $1164-1170$

21. Flachowsky G, Halle I and Aulrich K (2007) Long term feeding of Bt-corn - a tengeneration study with quails. Arch. Animal Nutri 59: 449-451.

22. Sissener NH, Sanden M, Bakke AM (2009) A long-term trial with Atlantic salmon (Salmo salar L.) fed geneticallymodified soy; focusing general health and performance before, during and after the parr-smolt transformation. Aquaculture 294: 108-117.

23. Netherwood T, Martin-Orue S, O'Donnell A (2004) Assessing the survival of transgenic plant DNSA in the human gastrointestinal tract. Nature Biotechnology 22: 204-209.

24. Holme IB, Wendt T, Holm PB (2013) Intragenesis and cisgenesis as alternatives to transgenic crop development. Plant Biotechnology J. 11: 395-405, and Schouten HJ, Krens FA, Jacobsen E (2006) Cisgenic plants are similar to traditionally bred plants. EMBO Reports. 7: 750-753.

25. Martin Luther King, Jr (1963) Letter from a Birmingham Jail

26. www.medicaldaily.com/pigs-brain-cells-kept-alive-after-slaughter-experiment-stirring-ethical-debate-423961; www.telegraph.co.uk/science/2018/05/06/yale-experiment-reanimate-dead-bains-promises-living-humans.
Copyright: C2018 Wassili JH. This is an open-access article distributed under the terms of the Creative Commons Attribution License, which permits unrestricted use, distribution, and reproduction in any medium, provided the original author and source are credited. 